
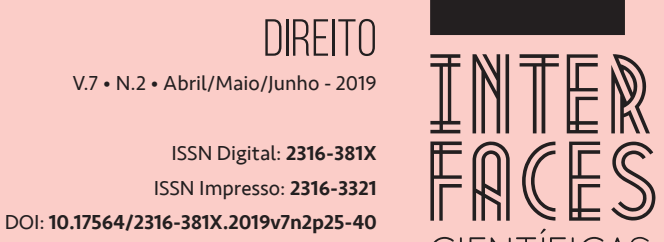

CIENTÍFICAS

\section{PENALIZAÇ̃̃o ADMINISTRATIVA ÀS EMPRESAS LICITANTES EM SERGIPE E A SUA CORRELAÇ̃̃O COM A CRISE ECONÔMICA CONTEMPORÂNEA}

ADMNISTRATIVE PENALTY TO SUGGESTING COMPANES IN SERGIPE AND ITS CORRELATION WITH THE CONTEMPORARY ECONOMIC CRISIS

PENALIZACIÓN ADMINISTRATIVA A LAS EMPRESAS LICITANTES EN SERGIPE Y SU CORRELACIÓN CON LA CRISIS ECONÓMICA CONTEMPORÁNEA

Bruno Rosceli Oliveira Dos Santos ${ }^{1}$ Luíz Ricardo Santana De Araújo Júnior ${ }^{2}$

\section{RESUMO}

O presente trabalho visa levantar informações acerca das sanções administrativas aplicadas às empresas licitantes com o Estado de Sergipe, bem como todas as etapas do procedimento previsto para a apuração de um eventual descumprimento contratual. Assim, são analisadas todas as penalidades previstas na legislação correspondente, Leis $n^{0} \mathrm{~s}$ 8.666/93 e 10.520/02 e Decreto Estadual $n^{\circ}$ 24.512/07, além dos fatos ensejadores das mesmas, verificando, também, a interferência da aplicação de penalidade no processo de rescisão unilateral do contrato e as possibilidades para a ocorrência desta previsão. Outro ponto relevante trazido no bojo deste artigo é a influência direta da crise econômica vivenciada pelo Estado sobre os contratos estabelecidos entre a Administração e particulares licitantes, fornecedores de bens ou serviços, acarretando um prejuízo recíproco pela falha ou inexecução do respectivo contrato, por parte do particular, e dos atrasos nos pagamentos, por parte da Administração. Face a esta problemática, procura-se trazer soluções viáveis que possibilitem uma melhora na situação econômica de ambas as partes contratantes visando driblar a inadimplência e, assim, trazer um fôlego maior ao Estado e às empresas licitantes para darem seguimento ao cumprimento de suas obrigações contratuais.

\section{PALAVRAS-CHAVE}

Sanções, Crise, Inadimplência, Administração. 


\section{ABSTRACT}

The aim of this paper is to present information's about administrative sanctions applied to bidder companies with the state of Sergipe, well as all procedure steps foreseen to canvass an eventual contractual noncompliance. Therefore, all penalties foreseen in the relative legislation are analyzed, laws $n^{\circ}$ s 8.666/93 e 10.520/02 and state decree $n^{\circ} 24.512 / 07$, beyond of the same motivation facts, but also verifying the application of penalties to the occurrence of the foreseen. Another relevant point brought in this article is the direct influence of the economic crisis experienced by the state about the contracts settle between the own administration and the biding companies, providers of goods and services, resulting in reciprocal injury by the fail or inexecution of the respective contract by the companies and the delay in the payments by the own administration. In front of this problematic situation, this paper intends to bring different solutions to make it possible an economic improvement between both contracting parts aiming to avoid defaults and thus to bring a better breath to the state and the biding companies to continue the compliance of the contractual duties.

\section{KEYWORDS}

Sanctions. Crisis. Defaults. Administration.

\section{RESUMEN}

El presente trabajo pretende levantar informaciones acerca de las sanciones administrativas aplicadas a las empresas licitantes con el Estado de Sergipe, así como todas las etapas del procedimiento previsto para el escrutado de un eventual incumplimiento contractual. Por lo tanto, se analizan todas las penalidades previstas en la legislación correspondiente, las Leyes No 8.666 / 93 y 10.520 / 02 y el Decreto Estatal $n^{0} 24.512$ / 07, además de los hechos que se plantean de las mismas, verificando también la interferencia de la aplicación de penalidad en el proceso de rescisión unilateral del contrato y las posibilidades para la ocurrencia de esta previsión. Otro punto relevante traído en el bojo de este artículo es la influencia directa de la crisis económica vivenciada por el Estado sobre los contratos establecidos entre la Administración y particulares licitantes, proveedores de bienes o servicios, acarreando un perjuicio recíproco por la falla o no ejecución del contrato, por parte del Estado en particular, y de los retrasos en los pagos por parte de la Administración. Frente a esta problemática, se procura traer soluciones viables que posibiliten una mejora en la situación económica de ambas partes contratantes para driblar el incumplimiento y, por lo tanto, traer un aliento mayor al Estado ya las empresas licitantes para dar seguimiento al cumplimiento de sus obligaciones contractuales. 


\section{PALABRAS CLAVE}

Sanciones, Crisis, Inadmisión, Administración.

\section{INTRODUCÇÃO}

Para evitar favorecimentos ilícitos e uso de influências financeiras para a contratação com o Poder Público, a Administração Pública criou procedimentos próprios garantidores dos princípios da legalidade, impessoalidade, igualdade, publicidade e probidade ou boa-fé administrativa. Trata-se da realização de procedimentos licitatórios para compras públicas, visualizando beneficiar a Administração, já que as empresas licitantes disputam entre si para que se chegue a um menor custo para os cofres públicos. O doutrinador Carvalho Filho (2012, p. 234), ao abordar sobre o tema, dispõe que:

Podemos conceituar a licitação como o procedimento administrativo vinculado por meio do qual os entes da Administração Pública e aqueles por ela controlados selecionam a melhor proposta entre as oferecidas pelos vários interessados, com dois objetivos - a celebração de contrato, ou a obtenção do melhor trabalho técnico, artístico ou científico.

Desta forma, percebe-se que a licitação deve atender o melhor interesse público, não se submetendo a quaisquer vontades dos particulares para a realização dos procedimentos de compras públicas. Também discorrendo sobre o tema, Di Pietro (2009, p. 350) aduz que “a licitação é um procedimento integrado por atos e fatos da Administração e atos e fatos do licitante, todos contribuindo para formar a vontade contratual", assim se voltando mais para a finalidade contratual do procedimento licitatório.

No Estado de Sergipe, as licitações são exercidas por diversos órgãos, porém, é na Secretaria de Estado do Planejamento, Orçamento e Gestão, onde se encontra o maior setor de licitações do estado, já que o mesmo é responsável por licitações referentes a todos os contratos centralizados bem como por todas as atas de registros de preço, além de realizar licitações de contratos próprios da maior parte dos Órgãos do Estado de Sergipe. Destaca-se também que a modalidade mais utilizada é o pregão eletrônico, trazendo agilidade ao procedimento, além de possibilitar que empresas do país inteiro possam participar da disputa, haja vista que é realizado por meio de um sistema acessível pela rede mundial de computadores - internet.

Ao participarem das licitações, as empresas licitantes se submetem à legislação vigente, presente na forma das leis de números 8.666/93, 10.520/02 e do decreto estadual n² 24.912/07, além dos princípios regedores das normas gerais da Administração. Caso não sejam observadas tais normas, a Administração está dotada de poder sancionador, com procedimento específico, garantindo o contraditório e a ampla defesa, para que sejam aplicadas as penalidades correspondentes às condutas infratoras das empresas licitantes. 
Porém, observado o atual contexto econômico do Estado de Sergipe, percebe-se que a própria Administração resta inadimplente na execução contratual para com as empresas vencedoras dos certames licitatórios, podendo gerar a inadimplência forçada de algumas empresas que não dispõem de meios suficientes para cumprir as disposições do contrato, caso não estejam recebendo a contraprestação devida por parte da Administração.

Assim, o presente trabalho destaca, também, que a possibilidade de um meio conciliatório para essas determinadas situações de inadimplência seria plenamente viável para tentar driblar a crise econômica contemporânea e trazer certo fôlego tanto para a Administração do Estado de Sergipe quanto para as empresas que contratam com esta, passando a discorrer esta ideia nos tópicos seguintes.

A metodologia utilizada, tendo por base os ensinamentos de Antônio Carlos Gil (2002), se trata da pesquisa pelo método indutivo, que tem natureza básica e cunho qualitativo, fundamentada em pesquisas em livros, artigos e outros meios de informação disponibilizados pela mídia brasileira, focando no tema em questão. Dadas as características da pesquisa, quanto ao objeto, parece ser adequado classificá-la como explicativa e ao mesmo tempo descritiva. Explicativa porque tem como objetivo principal tornar as matérias analisadas em dados de fácil compreensão, justificando e explicando os seus principais motivos. Será ainda utilizada a visão descritiva por conta da exposição de características claras e bem delineadas de determinadas situações ou direitos, envolvendo técnicas padronizadas e bem estruturadas de análise de seus dados. Quanto ao meio ela é classificada como documental.

\section{AS LICITAÇÕES NO ESTADO DE SERGIPE E AS SANÇÕES ADMINISTRATIVAS}

A Licitação é um procedimento que tem suas normas gerais previstas na lei 8.666 , de 21 de junho de 1993, que visa à contratação pertinente a obras, serviços, inclusive de publicidade, compras, alienações e locações no âmbito dos Poderes da União, dos Estados, do Distrito Federal e dos Municípios, bem como os fundos especiais, as autarquias, as fundações públicas, as empresas públicas, as sociedades de economia mista e demais entidades controladas direta ou indiretamente pela União, Estados, Distrito Federal e Municípios, como observado no artigo $1^{\circ}$ da referida lei. Di Pietro (2009, p. 354), ao argumentar sobre a base principiológica que rege a licitação, dispõe que:

Uma primeira observação é no sentido de que a própria licitação constitui um princípio a que se vincula a Administração Pública. Ela é uma decorrência do princípio da indisponibilidade do interesse público e que se constitui em uma restrição à liberdade administrativa na escolha do contratante; a Administração terá que escolher aquele cuja proposta melhor atenda ao interesse público.

Assim, percebe-se que, como unidade federativa que é, o Estado de Sergipe submete-se às regras gerais de licitação, além da necessidade de observância a todos os princípios regedores, sempre em busca do melhor interesse público. 
As licitações no Estado de Sergipe, em sua maioria, são realizadas sob a modalidade de Pregão Eletrônico, por meio de um software específico para proceder com todas as etapas do certame licitatório, sendo que, atualmente, este sistema é disponibilizado pelo Banco do Brasil, denominado "Sistema Licitações-e”, mediante contraprestação da Administração por pregão realizado. 0 maior setor de licitações do estado está presente na Secretaria de Estado do Planejamento, Orçamento e Gestão, denominado Superintendência Geral de Compras Centralizadas, onde é realizada a maioria das licitações referentes a Atas de Registro de Preços, referentes às contratações que visam à aquisição de bens e serviços do tipo menor preço por meio de uma única licitação, também, Contratos Centralizados para as contratações que visem interesse comum a todos os órgãos da Administração direta, para aqueles que desejem ser anuentes ao contrato, além de proceder com procedimentos licitatórios de algumas Secretarias de estado.

A base legal observada pela Administração se encontra presente nas Leis 8.666/93 e 10.520/02, denominadas a Lei Geral de Licitações e a Lei que institui a modalidade de Pregão, respectivamente. 0 artigo $1^{\circ}$ da Lei de Licitações prevê que:

Art. $1^{\circ}$ Esta Lei estabelece normas gerais sobre licitações e contratos administrativos pertinentes a obras, serviços, inclusive de publicidade, compras, alienações e locações no âmbito dos Poderes da União, dos Estados, do Distrito Federal e dos Municípios.

Parágrafo único. Subordinam-se ao regime desta Lei, além dos órgãos da administração direta, os fundos especiais, as autarquias, as fundações públicas, as empresas públicas, as sociedades de economia mista e demais entidades controladas direta ou indiretamente pela União, Estados, Distrito Federal e Municípios (BRASIL, 1993).

De tal modo, destaca o objeto a ser regulamentado pela mesma, além de trazer quais entes deverão segui-la. Percebe-se no parágrafo único que não só a Administração Direta tem o dever de observar as normas previstas na lei para licitações e contratos administrativos, mas também todas as pessoas jurídicas de direito público bem como as de direito privado que usufruem de recursos públicos.

Ao contratar com a Administração Pública do Estado de Sergipe, as empresas licitantes estão adstritas às normas previstas no edital e no contrato respectivo, não podendo agir em desconformidade com tais para não deslanchar em sanções administrativas. Estas estão previstas no capítulo IV, seção II, da Lei Geral de Licitações, dispondo sobre a ocorrência da das penalidades de multa, advertência, suspensão temporária e impedimento de licitar e contratar com a Administração e a declaração de inidoneidade. É perceptível que as sanções administrativas devem estar relacionadas à natureza do ato praticado, correspondentes ao grau do dano causado e conforme previsão legal para tanto, assim observa-se 0 artigo 87 da lei 8.666/93:

Art. 87. Pela inexecução total ou parcial do contrato a Administração poderá, garantida a prévia defesa, aplicar ao contratado as seguintes sanções:

I - advertência;

II - multa, na forma prevista no instrumento convocatório ou no contrato; 
III - suspensão temporária de participação em licitação e impedimento de contratar com a Administração, por prazo não superior a 2 (dois) anos;

IV - declaração de inidoneidade para licitar ou contratar com a Administração Pública enquanto perdurarem os motivos determinantes da punição ou até que seja promovida a reabilitação perante a própria autoridade que aplicou a penalidade, que será concedida sempre que o contratado ressarcir a Administração pelos prejuízos resultantes e após decorrido o prazo da sanção aplicada com base no inciso anterior.

$\S 1^{\circ}$ Se a multa aplicada for superior ao valor da garantia prestada, além da perda desta, responderá o contratado pela sua diferença, que será descontada dos pagamentos eventualmente devidos pela Administração ou cobrada judicialmente.

$\S 2^{\circ}$ As sanções previstas nos incisos I, III e IV deste artigo poderão ser aplicadas juntamente com a do inciso II, facultada a defesa prévia do interessado, no respectivo processo, no prazo de 5 (cinco) dias úteis.

$\S 3^{\circ} \mathrm{A}$ sanção estabelecida no inciso IV deste artigo é de competência exclusiva do Ministro de Estado, do Secretário Estadual ou Municipal, conforme o caso, facultada a defesa do interessado no respectivo processo, no prazo de 10 (dez) dias da abertura de vista, podendo a reabilitação ser requerida após 2 (dois) anos de sua aplicação (BRASIL, 1993).

Desta forma, sendo a penalidade mais branda a advertência e a mais severa a declaração de inidoneidade; haja vista que na ocorrência desta última a empresa perde, de uma certa forma, a credibilidade para com os contratantes, bem como a impossibilidade de contratar com a Administração Pública em todas as esferas; um dado importante é analisado no tocante à multa, prevista no instrumento convocatório ou no contrato, tendo em vista que é a única penalidade que pode dividir o campo sancionatório com outra, podendo ser cumulada às demais penalidades.

A lei que institui a modalidade de Pregão Eletrônico também prevê em seu artigo $7^{\circ}$ a possibilidade de sanção administrativa às empresas participantes dos certames licitatórios e traz um prazo de até cinco anos para a aplicação da penalidade de impedimento de licitar e contratar com a União, Estados, Distrito Federal ou Municípios, além do descredenciamento do Sistema de Cadastramento Unificado de Fornecedores (SICAF) ou demais cadastros de fornecedores, o que possibilita a verificação por todos os entes da respectiva situação da empresa.

No Estado de Sergipe, sob as normas do Decreto Estadual 24.912/07, são analisados os motivos ensejadores da sanção e descritos os valores correspondentes à multa aplicada, devendo ser analisada a dosimetria da penalidade com base no disposto no artigo 20 do respectivo decreto, que traz que:

Art. 20 Aos fornecedores que descumprirem total ou parcialmente os contratos celebrados com a administração pública estadual, e aos licitantes que cometam atos visando a frustrar os objetivos da licitação, serão aplicadas as seguintes sanções:

I - advertência: comunicação formal ao fornecedor, advertindo sobre o descumprimento de cláusulas contratuais e outras obrigações assumidas, e, conforme o caso, em que se confere prazo para a adoção das medidas corretivas cabíveis;

II - multa: deverá ser prevista no instrumento convocatório e/ou no contrato, observados 
os seguintes limites máximos:

a) 0,3\% (três décimos por cento) por dia, até o trigésimo dia de atraso, sobre o valor do fornecimento ou serviço não realizado, ou sobre a etapa do cronograma físico de obras não cumprido;

b) $10 \%$ (dez por cento) sobre o valor total ou parcial da obrigação não cumprida, com o conseqüente cancelamento da nota de empenho ou documento equivalente.

III - suspensão temporária de participação em licitação e impedimento de contratar com a Administração, por prazo não superior a 2 (dois) anos;

IV - declaração de inidoneidade para licitar ou contratar com a Administração Pública, enquanto perdurarem os motivos determinantes da punição ou até que seja promovida a reabilitação perante a própria autoridade que aplicou a penalidade, que será concedida sempre que o contratado ressarcir a Administração pelos prejuízos resultantes e depois de decorrido o prazo da sanção aplicada com base no inciso anterior (SERGIPE, 2007).

Assim, deve a Administração observar a conduta infratora para dosar a sanção para cada caso específico, sempre observada a base legal respectiva, bem como todos os princípios gerais que regem os atos administrativos, quais sejam, Legalidade, Impessoalidade, Moralidade, Publicidade e Eficiência. Outros pontos que também devem ser observados, estão presentes nos seis parágrafos do artigo supracitado, os quais explicitam a forma de aplicação das penalidades, as ocasiões que ensejam a aplicação das sanções de suspensão e impedimento de licitar ou contratar com a Administração Pública, além das causas para que o licitante seja declarado inidôneo.

\section{PROCEDIMENTO PARA A APURAÇ̃O DE DESCUMPRIMENTO CONTRATUAL E A RESCISÃO CONTRATUAL}

Para que sejam aplicadas as sanções previstas em lei e nas disposições contratuais ou editalícias, devem ser garantidos às empresas licitantes os direitos à ampla defesa e ao contraditório, para abrir margem para as mesmas contestarem as alegações imputadas bem como para a possibilidade de arguir fato novo que possa livrar da aplicação da penalidade específica. Destarte, deve ser observado procedimento específico para tanto e a Administração Pública do Estado de Sergipe tem o seu regulamentado pelo Decreto Estadual n² 24.912/07 (SERGIPE).

O contrato administrativo deve ser fiscalizado por um responsável designado pela autoridade administrativa, devendo este, observada conduta infratora ou inexecução contratual por parte da empresa licitante, comunicar fundamentadamente ao ordenador de despesas do órgão correspondente para a adoção de providências cabíveis. Quanto à competência para apurar os fundamentos da ocorrência da infração administrativa, o artigo $4^{\circ}$ do supracitado decreto dispõe que:

Art. $4^{\circ} \mathrm{A}$ apuração de responsabilidade na inexecução parcial ou total de obrigações assumidas por fornecedor é de competência do ordenador de despesas do órgão ou entida- 
de da administração pública estadual que firmou relação contratual de fornecimento de bens ou prestação de serviços com o fornecedor inadimplente (SERGIPE, 2007).

Ao analisar a Cartilha que trata das Sanções Administrativas a Licitantes e Contratados e Rescisão Contratual (s.d., p. 11) disponibilizada no site da Secretaria de Estado do Planejamento, Orçamento e Gestão, do Estado de Sergipe, observa-se que "cada órgão é responsável pela apuração de responsabilidade dos seus contratados, mesmo que a contratação seja efetivada através da emissão de nota de empenho". O empenho da despesa, conforme disposto no artigo 58 da lei no 4.320/64, é "o ato emanado de autoridade competente que cria para o Estado obrigação de pagamento pendente ou não de implemento de condição".

Recebida a notificação da infração administrativa cometida pela empresa licitante, o processo administrativo deve ser instaurado por ato administrativo do ordenador de despesas, geralmente por meio de uma portaria, a ser publicada no Diário Oficial do Estado, observados os princípios da publicidade e da transparência. Observa-se também, que para a condução do procedimento administrativo é designada uma comissão de servidores públicos, devendo esta, após a instauração do mesmo, notificar a empresa inadimplente para que, querendo, apresente a defesa dos fatos a ela imputados, respeitando o prazo de cinco dias para a sua apresentação, exceto se houverem indícios para a penalidade de declaração de inidoneidade, pelo fato de ser uma penalidade mais gravosa, assim sendo dez dias.

Instruído o processo, a comissão designada passa à elaboração de um relatório que antecede a decisão administrativa, conforme o artigo 18 do Decreto Estadual 24.512/07 (SERGIPE), dispondo que "finda a instrução, seguir-se-á o relatório, peça informativa e opinativa, que deverá conter o resumo do procedimento, sendo acrescido de proposta fundamentada de decisão". Em seguida, a autoridade competente decidirá com base nos autos, podendo concordar ou não com o relatório elaborado pela comissão processante, cabendo recurso desta decisão no prazo de cinco dias, observada a exceção para a defesa da declaração de inidoneidade.

Outro ponto a ser observado quanto ao descumprimento contratual, sendo cabível aplicação de penalidade, é pela utilização do Portal de Compras do Estado de Sergipe, denominado ComprasNet. $\mathrm{SE}$, que se trata de um acesso para a disputa referente às aquisições de bens e serviços por dispensa de licitação, sendo este portal gerido pela Superintendência Geral de Compras Centralizadas da Secretaria Geral de Planejamento, Orçamento e Gestão do Estado de Sergipe. Dispõe o parágrafo único do artigo $5^{\circ}$ do Decreto Estadual 24.912/07 que:

Art. $5^{\circ}$ Compete à Superintendência Geral de Compras Centralizadas a apuração da responsabilidade dos licitantes participantes dos certames por ela conduzidos.

Parágrafo único. A apuração de responsabilidade das pessoas físicas e jurídicas que participem de cotação eletrônica realizada no Portal de Compras do Estado de Sergipe - ComprasNet.SE, para as aquisições de bens e serviços com fulcro no art. 24, II, da Lei (Federal) nº 8.666, de 21 de junho de 1993, é de competência da Superintendência Geral de Compras Centralizadas, desde que a infração seja cometida antes da assinatura do contrato ou instrumento equivalente (SERGIPE, 2007). 
Neste caso, ocorrendo a conduta infratora da empresa antes da assinatura do contrato ou qualquer instrumento equivalente, será de competência da superintendência acima descrita a apuração da irregularidade bem como aplicação da sanção correspondente ao ato. Um exemplo a ser apresentado é no tocante a uma empresa vencedora de uma disputa de dispensa realizada no portal que ao ser, comunicada pelo órgão correspondente à contratação para a assinatura do contrato ou emissão do empenho, nega-se ao fazer sem justificativa plausível, ora, agindo de tal forma há um descaso total para com a Administração do Estado de Sergipe, haja vista a necessidade veemente para a aquisição dos materiais, e a dificuldade de todo o processo direcionado. Assinado o contrato ou instrumento equivalente, a competência será do órgão público fiscalizador do contrato, exceto nas contratações centralizadas e referentes a registro de preços, cuja competência também é da superintendência supracitada.

Ao findar o processo administrativo e verificada a aplicação de penalidade à empresa licitante, restam questionamentos sobre a rescisão automática do contrato. Sobre esta análise, Fernando Moreno Machado (2014, p. 93) aduz que:

\begin{abstract}
Um apontamento prévio que merece ser feito é no sentido de que, a princípio, não parece razoável que, no bojo da contratação que deu origem à sanção aplicada ao particular, a rescisão não seja efetivada, tendo em vista que os pressupostos de aplicação são os mesmos, quais sejam: a inexecução total ou parcial do contrato (além das hipóteses do artigo 88), consoante redação dos incisos I e II do artigo 78, da Lei das Licitações. Se a falha cometida pelo particular é grave o suficiente para que aplicadas as penalidades mais graves, evidente que também o será para motivar a rescisão do contrato. 0 que deve ficar claro, todavia, é que não há relação de causa e efeito entre o apenamento e a rescisão.
\end{abstract}

Destarte, observando a análise feita, percebe-se que o fato de ter sido aplicada a penalidade à empresa licitante não gera automaticamente a rescisão do contrato respectivo, podendo a Administração prosseguir com o contrato normalmente, a depender da penalidade aplicada, haja vista se subentende que uma aplicação mais severa, como a declaração de inidoneidade, venha a gerar a rescisão do contrato, porém, outras a exemplo da advertência e da multa, podem não afetar diretamente a vigência do contrato. Além do mais, a Administração Pública não depende da resolução do procedimento específico de apuração de descumprimento contratual para a rescisão unilateral, demonstrada a irregularidade e inconteste sua veracidade, o gestor do contrato pode, motivadamente, rescindir o contrato, convocando a licitante seguinte na ordem de classificação do certame licitatório.

Carvalho Filho (2012), ao tratar da rescisão contratual, comenta que existem motivos ensejadores da rescisão unilateral pela Administração Pública, pautando-se no interesse da própria e no cumprimento do contrato pelo particular. Assim, verificando-se a condutas que levem ao ensejo de infração cometidas pelo particular, bem como a inviabilidade de seguimento no contrato por parte da Administração, sempre pautada no interesse público, dão causa à possibilidade de rescisão unilateral contratual. 


\section{A CRISE ECONÔMICA CONTEMPORÂNEAE SEUS REFLEXOS NA EXECUÇÃO DOS CONTRATOS}

Inconteste que nos últimos anos a crise que assolou o Brasil interferiu diretamente tanto na Administração Pública do Estado de Sergipe quanto nas empresas licitantes com a mesma, sendo que atualmente, apesar do país em suas generalidades ter apresentado uma melhora considerável no aspecto econômico, o citado estado não apresentou melhoras consideráveis em sua economia estatal.

Um fato consequência da crise econômica presente no Estado de Sergipe é observado ao se verificar a inadimplência estatal para com seus contratados fornecedores de bens ou serviços, implicando muitas vezes na execução do contrato a depender do porte da empresa e da capacidade de manter a execução do contrato com tantos atrasos nos pagamentos. Ocorre que, ficando impossibilitada de executar o contrato por conta da inadimplência da Administração Pública, a empresa falha na execução do contrato, configurando-se como infratora dos ditames editalícios ou contratuais, podendo ensejar à aplicação de penalidade equivalente até mesmo a uma sanção pecuniária (multa), sendo irrelevante que ela se encontre em situação prejudicial dada como consequência dos atrasos nos pagamentos correspondentes, possibilitando, como fim mais gravoso, à falência.

Ao tratar da teoria da imprevisão, Elias Rosa (2005) traz o Fato da Administração como causa predominante para a rescisão contratual, fundamentando que incide diretamente no contrato, impedindo sua execução regular, ainda se equiparando à força maior, no tocante aos seus efeitos, citando como exemplo a aqui já comentada interrupção prolongada e imotivada dos pagamentos devidos ao contratado. Dispondo sobre o mesmo tema, ao abordar sobre a necessidade de continuidade ao contrato, Di Pietro (2009, p. 281) dispõe que:

Essa regra admite exceção pela aplicação da teoria do fato da Administração, quando sua conduta tornar impossível a execução do contrato ou causar ao contratado um desequilíbrio econômico extraordinário, que não seria razoável exigir que suportasse, pela desproporção entre esse sacrifício e o interesse público a atingir pela execução do contrato.

Ao observar a proporção do dano causado decorrente de atraso nos pagamentos, a empresa pode requerer judicialmente pela rescisão contratual, até porque a depender do poder econômico da empresa, pode gerar consequências internas mais graves à mesma, a exemplo das empresas de pequeno porte e microempresas, haja vista que a depender do valor do contrato e da proporção que ele circula a renda mensal da empresa, a simples falta de pagamento pode gerar consequências severas.

Carvalho Filho (2012), argumentando sobre a rescisão unilateral dos contratos administrativos, comenta sobre a exceção de contrato não cumprido ou exceptio non adimpleti contractus, que é prevista no artigo 476 do Código Civil. Segundo o doutrinador, a referida exceção significa que caso uma parte da relação contratual não esteja cumprindo com sua parte, também, não poderá exigir que a outra o faça, tratando-se de um meio de defesa quando uma parte é instada pela outra. Antes, entendia-se que tal meio de defesa não poderia beneficiar o contratado da Administração Pública, pelo princípio da continuidade do serviço público, porém, a moderna 
doutrina vislumbra seu entendimento no sentido de que a não observância da situação contratual pode gerar injustiças ao contratado.

A Lei 8.666/93 prevê que, verificado atraso nos pagamentos correspondentes à execução contratual superior a 90 dias, a contratada da Administração poderá requerer a rescisão do contrato ou somente a suspensão do cumprimento da obrigação. Carvalho Filho (2012, p.196), ao comentar sobre o dispositivo argumenta que:

O dispositivo, como se vê , parece considerar que, antes de 90 dias, não possa o particular reclamar do atraso nos pagamentos. Entendemos, entretanto, que, em situações especiais, se o prejudicado, mesmo antes desse prazo ficar impedido de dar continuidade ao contrato por força da falta de pagamento, tem ele direito à rescisão do contrato com culpa da Administração. Fora daí, é admitir-se a ruína do contratado por falta contratual imputada à outra parte, o que parece ser inteiramente iníquo e injurídico.

Outrossim, observa-se que, antes do prazo estabelecido, seria retrógrado ao conceito de justiça impossibilitar que a empresa licitante extremamente prejudicada e na iminência de sofrer sérias consequências econômicas não pudesse pleitear a rescisão do respectivo contrato com a Administração.

Todavia, algumas empresas tentam suportar a inadimplência da Administração do Estado de Sergipe, tendo em vista a inviabilidade de perder um contrato financeiramente vultoso que gera um lucro maior para elas, até com o atraso nos pagamentos. Correndo esse risco, algumas acabam falhando ou atrasando a execução do contrato e assim, os responsáveis pela fiscalização do contrato comunicam a autoridade competente a fim de que seja instaurado procedimento de apuração de descumprimento contratual, observando-se que na maioria das vezes geram penalidades às empresas que de certa forma já são penalizadas pelos atrasos nos pagamentos frente a Administração do Estado.

Mesmo sem receber da Administração, caso o contratado não informe à autoridade superior da inadimplência, da suspensão dos serviços ou solicitação de rescisão contratual, deverá dar continuidade ao contrato, e é aí que os fatos ensejadores de penalidades aparecem. Para dar seguimento sem deslize nas obrigações contratuais, o contratado deve dispor de um poderio econômico satisfatório para manter sua empresa, porém, na maioria dos casos, as empresas acabam até por falir, em decorrência da falta de pagamento por seus serviços prestados, correndo o risco de sofrer aplicação de penalidade mais gravosa e intensificar ainda mais os seus prejuízos.

Frente à essa problemática, o procedimento para apuração de descumprimento contratual do Estado de Sergipe se torna meramente frio e injusto ao deixar de observar as intempéries vivenciadas pelas empresas licitantes em decorrência da falta de pagamento. De tal modo, não se vislumbra qualquer meio satisfatório de resolução dos conflitos entre a Administração do Estado e suas contratadas, tornando-se veemente a necessidade de inclusão de uma etapa de conversação entre ambas no procedimento a ser instaurado, para tentar obter uma solução financeiramente mais viável, haja vista que as consequências atingem diretamente no melhor interesse público.

Marinoni (2015) traz conceitos importantes sobre as formas de resolução de litígios, abordando acerca dos métodos heterocompositivos e autocompositivos. Ambos são meios para se tentar resolver 
conflitos, porém os primeiros são realizados mediante interferência direta de terceiros. A forma autocompositiva é uma forma de solução de litígios em que as próprias partes interessadas acordam entre si a fim de que tenha um resultado benéfico recíproco. Diante disso, Marinoni (2015, p. 180) aborda que:

Ao lado das formas hetererocompositivas, são admissíveis também meios autocompositivos de resolução de conflitos, em que as partes interessadas resolvem por si mesmas a ameaça ou crise de colaboração na realização do direito material. Embora de um ponto de vista cultural possam ser vistos como sintomas de crises relativas à verdade e à certeza, os meios autocompositivos (que entram no gênero Alternative Dispute Resolution) são normalmente apresentados como tendências gerais em termos de direito comparado e são bastante incentivados no novo Código de Processo Civil.

Apesar de dar ênfase ao direito processual civil, a matéria suscitada traz relevante importância de um modo geral para a possibilidade de sua aplicação em outros ramos do direito. No tocante à Administração pública do Estado de Sergipe, como método de resolução de conflitos decorrentes de inadimplência recíproca, ou dos efeitos diretos do atraso nos pagamentos, a forma autocompositiva seria plenamente viável a ser aplicada, haja vista que o princípio da Supremacia do Interesse Público não restaria violado, já que uma conversação com a finalidade de resolução de conflitos entre ambas as partes nada tem a prejudicar o contrato vigente, pelo contrário, encontraria uma solução mais viável para que o mesmo pudesse ser executado da melhor maneira.

Em Sergipe, nos Órgãos integrantes da Administração, nos quais tramitam os procedimentos de apuração de descumprimento contratual, ainda não foi implantado qualquer método de resolução de conflitos pelos meios sobrescritos. Porém, na Secretaria de Estado do Planejamento, Orçamento e Gestão, a situação comunicada para a instauração de processo é passada ao gestor competente para que analise a viabilidade, possibilitando que fiscalize a real situação comunicada, bem como a possibilidade de seguimento à execução contratual, face a urgência ou necessidade dos produtos ou serviços a serem disponibilizados à Administração.

Assim, apesar de não ser uma forma incluída no próprio procedimento, haja vista que para isso o Decreto Estadual 24.912/07 deve ser alterado de acordo com as formalidades legais pertinentes, percebe-se o início de uma análise mais criteriosa dos fatos imputados às empresas licitantes e uma concepção da busca pelo melhor interesse público pautada na necessidade de continuidade da execução contratual ao invés da pretensão punitiva exacerbada do Estado.

\section{CONSIDERAÇÕES FINAIS}

As empresas licitantes ao contratar com o Estado de Sergipe se vinculam às normas previstas no edital do procedimento licitatório bem como na legislação vigente. Descumprindo os dispositivos contratuais, sujeitam-se ao procedimento de apuração de descumprimento contratual, na iminência da aplicação de sanções administrativas pela autoridade competente. 
Ocorre que a Administração Pública do Estado de Sergipe vive um momento econômico extremamente delicado, reflexo da crise econômica que assolou o país nos últimos anos, perceptível pelos atrasos constantes nos pagamentos dos seus servidores e empresas contratadas fornecedoras de bens e serviços. Assim, algumas empresas são drasticamente prejudicadas, interferindo diretamente no andar contratual, dificultando cada vez mais a execução do objeto do contrato por conta da inadimplência estatal.

Todavia, vislumbra-se no procedimento para a apuração dos atos infracionais cometidos pelas empresas licitantes uma certa falta de adequação quanto a possíveis soluções para alguns casos específicos. Isto porque, principalmente no atual contexto de crise vivenciada pelo Estado e que acaba passando vários meses sem realizar pagamentos às suas contratadas, a legislação fica inerte para a necessidade pública, haja vista que alguns bens ou serviços fornecidos são extremamente essenciais para a Administração, bem como para sua maior beneficiária, a sociedade. Deste modo, acaba havendo um prejuízo considerável para a realização de uma nova contratação, não só pela mora para tanto, mas também pelas custas que acarretarão aos cofres públicos.

De forma a se concluir o presente trabalho, torna-se cabível a propositura de uma forma autocompositiva de resolução dos conflitos gerados por inadimplência recíproca. Observa-se que caso a empresa falhe na execução do contrato cabe aplicação de penalidade, porém se deve verificar, também, a contribuição que a Administração gerou para que a sua contratada viesse a falhar ou chegar até ao ponto de deixar de executar o respectivo contrato e assim analisar soluções mais viáveis para findar o problema contratual, com a finalidade de driblar, licitamente, a crise econômica e desafogar a máquina estatal.

\section{REFERÊNCIAS}

BRASIL. Lei $\mathbf{n}^{\mathbf{0}} \mathbf{4 . 3 2 0}$, de 17 de março de 1964. Estatui normas gerais de direito financeiro para elaboração e controle dos orçamentos e balanços da União, dos Estados, dos Municípios e do Distrito Federal. Disponível em: http://www.planalto.gov.br/ccivil_03/leis/L4320.htm. Acesso em: out. 2017.

BRASIL. Lei n 8.666, de 21 de junho de 1993. Regulamenta o art. 37, inciso XXI, da Constituição Federal, institui normas para licitações e contratos da Administração Pública e dá outras providências. Disponível em: http://www.planalto.gov.br/ccivil_03/leis/L8666cons.htm. Acesso em: out. 2017.

BRASIL. Código Civil. Lei n⿳0 10.406, de 10 de janeiro de 2002. São Paulo: Revista dos Tribunais, 2002.

BRASIL. Lei n. 10.520, de 17 de julho de 2002. Institui a modalidade de licitação denominada pregão, 
para aquisição de bens e serviços comuns. Diário Oficial, Brasília, Distrito Federal, 17 jul. 2002.

Disponível em: http://www.planalto.gov.br/ccivil_03/Leis/2002/L10520.htm. Acesso em: out. 2017.

CARVALHO FILHO, José dos Santos. Manual de Direito Administrativo. São Paulo: Atlas, 2012.

DI PIETRO, Maria Sylvia Zanella. Direito administrativo. São Paulo: Atlas, 2009.

GIL, Antônio Carlos. Como elaborar projetos de pesquisa. 4. ed. São Paulo: Atlas, 2002.

\section{MACHADO, Fernando Moreno. As sanções administrativas da Lei de Licitações e a}

desconsideração da personalidade jurídica. São Paulo: Biblioteca Digital USP, 2014.

MARINONI, Luiz Guilherme; ARENHART, Sérgio Cruz; MITIDIERO, Daniel. Novo curso de processo civil: teoria do processo civil. Volume 1. São Paulo: Revista dos Tribunais, 2015.

ROSA, Márcio Fernando Elias. Direito administrativo. São Paulo: Saraiva, 2005.

SERGIPE. Decreto $\mathbf{n}^{\circ}$ 24.912, de 20 de dezembro de 2007. Dispõe normas regulamentares sobre o procedimento administrativo de apuração de infrações administrativas cometidas por licitantes e contratados da Administração Pública estadual; sobre a aplicação de penalidades e institui o Cadastro de Fornecedores Impedidos de Licitar e Contratar com a Administração Pública Estadual. Disponível em: http://www.comprasnet.se.gov.br/images/banners/decretos/decreto_estadual_ n24912.pdf. Acesso em: out. 2017.

SERGIPE. Sanções administrativas a licitantes e contratados. Cartilha. Disponível em: http://www. comprasnet.se.gov.be/imagens/cartilha_sancoes_e_rescisões.pdf. Acesso em: out. 2017. 


\section{Como citar este artigo:}

DOS SANTOS, Bruno Rosceli Oliveira; JÚNIOR, Luíz Ricardo Santana De Araújo. PENALIZAÇÃO ADMINISTRATIVA ÀS EMPRESAS LICITANTES EM SERGIPE E A SUA CORRELAÇÃO COM A CRISE ECONÔMICA CONTEMPORÂNEA. Interfaces Científicas - Direito, Aracaju, v. 7, n. 2, p. 27-41, abr/mai/jun. 2019. DOI: $10.4025 /$ actascieduc. v4111.34184. Acesso em: 24 mar. 2019.

1 Bel. em Direito pela Universidade Tiradentes, Advogado OAB-SE n 11.646, Assessor Chefe da Superintendência de Compras Centralizadas da Secretaria de Planejamento Orçamento e Gestão do Estado de Sergipe, Membro do Conselho da Jovem Advocacia-OAB/SE.

E-mail: brunorosceliadv@gmail.com.

2 Mestre em Direitos Humanos pela Universidade Tiradentes (PPGD/UNIT). Bacharel em Direito pela Universidade Tiradentes. Assessor Jurídico do Ministério Público da União, Procuradoria da República em Sergipe. Professor Assistente I da Universidade Tiradentes (Processo Civil e Direito Tributário)E-mail: Irsaj@hotmail.com. 
